\title{
How to minimize conversion to open surgery during laparoscopic liver resection: the point of view of hemostasis
}

\author{
Seunghwan Lee \\ Department of Surgery, Kyung Hee University Hospital at Gangdong, Kyung Hee University School of Medicine, Seoul, Korea
}

It has been 30 years since laparoscopic liver resection was first introduced, and, in the beginning, wedge resection or nonanatomical liver resection was mainly performed. With the development of surgical techniques and instruments, many centers are currently performing major liver resections and even difficult anatomical liver resections such as segment VI, VII, and VIII and caudate segment. However, laparoscopic surgery has limitations in instrument manipulation, and due to the nature of liver resection surgery, massive bleeding may occur. Therefore, it is necessary to make efforts to minimize the bleeding and reduce the conversion to laparotomy due to bleeding.

Keywords: Laparoscopy, Hepatectomy, Hemostasis, Conversion to open surgery
Received November 29, 2021

Revised December 3, 2021

Accepted December 7, 2021

Corresponding author

Seunghwan Lee

Department of Surgery, Kyung Hee University Hospital at Gangdong,

Kyung Hee University School of Medicine, 892 Dongnam-ro, Gangdong-gu, Seoul 05278, Korea Tel: $+82-2-440-6256$

Fax: +82-2-440-7145

E-mail: histones@hanmail.net, histones1@khnmc.or.kr ORCID:

https://orcid.org/0000-0002-5516-0947

Copyright $\odot$ The Korean Society of Endoscopic and Laparoscopic Surgeons.
This is an Open Access article distributed under the terms of the Creative Commons Attribution Non-Commercial License (http:// creativecommons.org/licenses/by-nc/4.0/) which permits unrestricted non-commercial use, distribution, and reproduction in any medium, provided the original work is properly cited. to conversion to open surgery quickly [7].

It is necessary to accurately understand the intrahepatic location of the tumor and the vascular structures around it through images such as computed tomography before surgery; based on this, the surgical resection margin can be predicted. Exact placement of the trocar so that it can be resected comfortably along the predicted surgical margin allows the operator to operate in a comfortable position, which can help prevent bleeding [8].

In case of bleeding, inflow control by intracorporeally or extracorporeally Pringle maneuver is an established method to decrease bleeding during LLR and is widely used [9]. Outflow controls by Trendelenburg positioning, lower central venous pressure ( $<5 \mathrm{mmHg}$ ), slightly increasing intra-abdominal $\mathrm{CO}_{2}$ pressure (10-14 $\mathrm{mmHg}$, or hanging maneuver are a helpful method to 
minimize bleeding and can be easily applied [7,10].

In addition, surgeons should be experienced with the use of all surgical devices for LLR and should be skillful in laparoscopic suture before starting LLR [10]. The technical limitations of LLR are continuously being overcome, and better instruments are expected to be developed in the future to help in the operation. More prospective data are required to confirm feasibility and safety of LLR.

\section{NOTES}

\section{Conflict of interest}

The author has no conflicts of interest to declare.

\section{Funding/support}

None.

\section{REFERENCES}

1. Cheung TT, Han HS, She WH, et al. The Asia Pacific Consensus Statement on Laparoscopic Liver Resection for Hepatocellular Carcinoma: a report from the 7th Asia-Pacific Primary Liver Cancer Expert Meeting held in Hong Kong. Liver Cancer 2018;7:28-39.

2. Wakabayashi G, Cherqui D, Geller DA, et al. Recommendations for laparoscopic liver resection: a report from the second international consensus conference held in Morioka. Ann Surg 2015;261:619-629.

3. Shin H, Cho JY, Han HS, et al. Risk factors and long-term implica- tions of unplanned conversion during laparoscopic liver resection for hepatocellular carcinoma located in anterolateral liver segments. J Minim Invasive Surg 2021;24:191-199.

4. Lee JY, Rho SY, Han DH, Choi JS, Choi GH. Unplanned conversion during minimally invasive liver resection for hepatocellular carcinoma: risk factors and surgical outcomes. Ann Surg Treat Res 2020;98: 23-30.

5. Silva JP, Berger NG, Yin Z, et al. Minimally invasive hepatectomy conversions: an analysis of risk factors and outcomes. HPB (Oxford) 2018;20:132-139.

6. Stiles ZE, Glazer ES, Deneve JL, Shibata D, Behrman SW, Dickson PV. Long-term implications of unplanned conversion during laparoscopic liver resection for hepatocellular carcinoma. Ann Surg Oncol 2019;26:282-289.

7. Costi R, Scatton O, Haddad L, et al. Lessons learned from the first 100 laparoscopic liver resections: not delaying conversion may allow reduced blood loss and operative time. J Laparoendosc Adv Surg Tech A 2012;22:425-431.

8. Takagi K, Kuise T, Umeda Y, et al. Laparoscopic liver resection of segment seven: a case report and review of surgical techniques. Int J Surg Case Rep 2020;73:168-171.

9. Komeda K, Hayashi M, Inoue $\mathrm{Y}$, et al. Clinical usefulness of endo intestinal clips during Pringle's maneuver in laparoscopic liver resection: a technical report. Surg Laparosc Endosc Percutan Tech 2013;23: e103-e105.

10. Tranchart H, O’Rourke N, Van Dam R, et al. Bleeding control during laparoscopic liver resection: a review of literature. J Hepatobiliary Pancreat Sci 2015;22:371-378. 